\title{
High tidal volume mechanical ventilation-induced lung injury in rats is greater after acid instillation than after sepsis-induced acute lung injury, but does not increase systemic inflammation: an experimental study
}

Jan Willem Kuiper ${ }^{1,2^{*}}$, Frans B Plötz ${ }^{1,3}$, AB Johan Groeneveld ${ }^{4}$, Jack J Haitsma ${ }^{2}$, Serge Jothy ${ }^{5}$, Rosanna Vaschetto ${ }^{1,2,6}$ , Haibo Zhang ${ }^{2}$ and Arthur S Slutsky²

\begin{abstract}
Background: To examine whether acute lung injury from direct and indirect origins differ in susceptibility to ventilator-induced lung injury (VILI) and resultant systemic inflammatory responses.

Methods: Rats were challenged by acid instillation or $24 \mathrm{~h}$ of sepsis induced by cecal ligation and puncture, followed by mechanical ventilation (MV) with either a low tidal volume (Vt) of $6 \mathrm{~mL} / \mathrm{kg}$ and $5 \mathrm{~cm} \mathrm{H}_{2} \mathrm{O}$ positive end-expiratory pressure (PEEP; LVt acid, LVt sepsis) or with a high Vt of $15 \mathrm{~mL} / \mathrm{kg}$ and no PEEP (HVt acid, HVt sepsis). Rats sacrificed immediately after acid instillation and non-ventilated septic animals served as controls. Hemodynamic and respiratory variables were monitored. After 4 h, lung wet to dry (W/D) weight ratios, histological lung injury and plasma mediator concentrations were measured.

Results: Oxygenation and lung compliance decreased after acid instillation as compared to sepsis. Additionally, W/ D weight ratios and histological lung injury scores increased after acid instillation as compared to sepsis. MV increased W/D weight ratio and lung injury score, however this effect was mainly attributable to HVt ventilation after acid instillation. Similarly, effects of HVt on oxygenation were only observed after acid instillation. HVt during sepsis did not further affect oxygenation, compliance, W/D weight ratio or lung injury score. Plasma interleukin-6 and tumour necrosis factor- $\alpha$ concentrations were increased after acid instillation as compared to sepsis, but plasma intercellular adhesion molecule-1 concentration increased during sepsis only. In contrast to lung injury parameters, no additional effects of HVt MV after acid instillation on plasma mediator concentrations were observed.
\end{abstract}

Conclusions: During MV more severe lung injury develops after acid instillation as compared to sepsis. HVt causes VILI after acid instillation, but not during sepsis. However, this differential effect was not observed in the systemic release of mediators.

Keywords: Ventilator-induced lung injury, acute lung injury, sepsis, cytokines, lung histology, mechanical ventilation.

\footnotetext{
* Correspondence: jw.kuiper@vumc.nl

${ }^{1}$ From the Department of Paediatric Intensive Care, VU University Medical

Centre, Amsterdam, The Netherlands

Full list of author information is available at the end of the article
} 


\section{Background}

Acute lung injury and its most severe manifestation, the acute respiratory distress syndrome (ARDS), result from direct or indirect pulmonary insults. A direct, primary or pulmonary insult directly affects the lung parenchyma. In contrast, an indirect, secondary or extrapulmonary insult follows from an acute systemic inflammatory response [1]. In a clinical study, involving patients suffering from pneumonia, peritonitis or polytrauma, these types of injury differed in terms of respiratory mechanics and response to positive end-expiratory pressure [2]. Animal experiments showed additional differences in the pulmonary inflammatory response, ultrastructural characteristics, apoptosis and respiratory mechanics [3-6]. The distinction between these insults may have therapeutic implications regarding ventilator settings [7-9]. For example, predominant consolidation of the lung in direct injury as opposed to oedema and alveolar collapse in indirect injury might imply the potential for greater ventilator-lung induced injury (VILI) in the former since alveolar recruitability would be less and overdistension greater for a given tidal volume $[2,10,11]$. However, this concept is highly controversial [12-14]. One of the consequences of VILI is an increase in translocation of mediators involved in lung inflammation into the systemic circulation, thereby potentially contributing to remote organ injury and failure [15-20]. It is unknown, however, whether direct vs. indirect injuries differ in this respect, but greater propensity for VILI in the former could be associated with a greater systemic inflammatory response.

We hypothesize that the harmful effects of different ventilation strategies depend on the type of underlying lung injury. In this study we therefore set out to examine the effects of different ventilatory strategies on lung injury and systemic mediator release in direct and indirect pulmonary injury in rats. Direct pulmonary injury was induced by acid aspiration, regarded as an important risk factor for the development of ARDS [21-24]. Indirect pulmonary injury was generated by cecal ligation and perforation, a widely used animal model of sepsis - one of the main risk factors for ARDS [21]. We measured plasma mediators involved in inflammation, chemotaxis, cell adhesion and fibrinolysis that relate to remote organ dysfunction and outcome of acute lung injury [15-18,25-31].

\section{Methods}

Animal preparation

Animals were treated according to the Canadian national guidelines and with approval of the Animal Care Committee of St Michaels Hospital. Male Sprague Dawley rats (Charles Rivers, St Constan, QC, Canada) weighing 290-320 g were anesthetized with xylazine (Bayer, Toronto, ON, Canada) $10 \mathrm{mg} / \mathrm{kg}$ and ketamine (Bimeda-MTC, Cambridge, ON, Canada) $100 \mathrm{mg} / \mathrm{kg}$ given intraperitoneally. Anaesthesia was maintained by intravenous xylazine $1 \mathrm{mg} / \mathrm{kg} / \mathrm{h}$, ketamine $20 \mathrm{mg} / \mathrm{kg} / \mathrm{h}$; muscle relaxation was achieved by intravenous pancuronium bromide (Sabex Inc, QC, Canada) $0.6 \mathrm{mg} / \mathrm{kg} / \mathrm{h}$. During surgical procedures and ventilation, rats were supine on a heating pad and body temperature was maintained at $37^{\circ} \mathrm{C}$. For blood sampling, fluid infusion and arterial blood pressure measurements, catheters were inserted into the right carotid artery and tail vein before stabilization. The arterial catheter was connected to a pressure transducer for continuous measurement of arterial blood pressure. During mechanical ventilation (MV) all animals received a continuous infusion of normal saline to maintain mean arterial blood pressure > $60 \mathrm{mmHg}$, and for patency of intravenous lines.

A pilot study was undertaken to establish the acid instillation protocol. Briefly, after anaesthesia and tracheotomy, a $14 \mathrm{G}$ canula was inserted into the trachea and connected to a ventilator (Servo 300, Siemens, Munich, Germany); set to deliver a tidal volume (Vt) of $6 \mathrm{~mL} / \mathrm{kg}$ and a positive end-expiratory pressure (PEEP) of $5 \mathrm{~cm} \mathrm{H}_{2} \mathrm{O}$. One animal was ventilated per ventilator per experiment. Arterial and venous catheters were inserted and hydrochloric acid $(\mathrm{HCl}, \mathrm{pH} 2.0), 1 \mathrm{ml} / \mathrm{kg}$, was rapidly instilled intratracheally at baseline using an aerosolizer (PennCentury Inc, Philadelphia, PA, USA). Instillation was followed by a recruitment manoeuvre (increase in PEEP to $25 \mathrm{~cm} \mathrm{H}_{2} \mathrm{O}$ for 5 breaths). Rats were subsequently stabilized for 10 minutes and then randomized. Acid aspiration control rats received acid instillation alone after which they were sacrificed after the recruitment manoeuvre. Rats did not survive acid instillation without subsequent MV due to technical and ethical limitations; inclusion of time-matched controls was therefore impossible. The mortality rate of acid instillation was $13 \%$ before randomisation.

Sepsis was induced as follows. With the animal spontaneously breathing 40\% oxygen, a laparotomy through a midline incision using an aseptic technique was performed. The coecum was ligated just below the ileocecal valve with 3-0 silk ligature, so that intestinal continuity was maintained. Using a 14-Gauge needle, the coecum was perforated in two locations, $1 \mathrm{~cm}$ apart, on the antimesenteric surface of the coecum, and the coecum was gently compressed until faeces were extruded. The bowel was then returned to the abdomen and the incision was closed using 4-0 silk ligature for both the muscle layer and skin. Subsequently, rats received $30 \mathrm{~mL} / \mathrm{kg} 0.9 \%$ saline in the scruff of the neck and buprenorphine $30 \mu \mathrm{g} / \mathrm{kg}$ 
subcutaneously (Schering-Plough, Hertfordshire, UK). The rats breathed $40 \%$ oxygen until recovery from anaesthesia, and then were placed back in a cage with free access to food and water. Eight hours after surgery, rats received a $30 \mathrm{~mL} / \mathrm{kg} 0.9 \%$ saline bolus i.p. Mortality rate of the model prior to randomisation was $6 \%$. Twenty-four hrs after the induction of sepsis, rats were anaesthetized and tracheotomy was performed, with a canula (14 gauge) inserted into the trachea. Rats were connected to a ventilator; arterial and venous catheters were inserted followed by a 10-minute stabilization period with ventilation using Vt $6 \mathrm{~mL} / \mathrm{kg}$ and PEEP $5 \mathrm{~cm} \mathrm{H}_{2} \mathrm{O}$.

\section{Experimental protocol}

After stabilization, rats were randomly allocated to one of 4 groups: MV with either a low $\mathrm{Vt}(6 \mathrm{~mL} / \mathrm{kg})$ and PEEP $5 \mathrm{~cm} \mathrm{H}_{2} \mathrm{O}$ ( $\mathrm{n}=10$ per group) (LVt acid and LVt sepsis) or a high Vt $(15 \mathrm{~mL} / \mathrm{kg})$, no PEEP ( $\mathrm{n}=10$ per group) (HVt acid and HVt sepsis). Eight rats were immediately sacrificed after acid instillation (acid). Ten rats served as non-ventilated septic controls (sepsis) and were sacrificed $28 \mathrm{hr}$ after induction of sepsis. Tidal volumes were selected that have shown to cause lung injury or proven to be non-injurious in rats [15-17], and inspiratory/expiratory ratio was 1:2. Normocapnia was maintained by adjusting respiratory rate. The fraction of inspired oxygen was set at 0.4 and increased when necessary in ventilated groups. At the end of the experiment a blood sample was taken and animals were sacrificed with an overdose of ketamine/xylazine.

Rats were ventilated for 4 hrs during which blood pressure and heart rate were measured continuously. Arterial blood samples were taken 30 min after randomization and every hour for blood gas analysis (Ciba Corning Model 248 blood gas analyser, Corning Medical, Medfield, MA, USA). For each blood sample a volume of maximum $100 \mu \mathrm{l}$ was necessary. An equal amount of normal saline was administered intravenously to compensate for the fluid loss. Total respiratory dynamic compliance $\left(\mathrm{ml} / \mathrm{cm} \mathrm{H}_{2} \mathrm{O}\right)$ was calculated by Vt/(Pplat-PEEP), where Vt is the applied tidal volume and Pplat is the plateau pressure measured every 30 minutes during an inspiratory pause on the ventilator. Interleukin-6 (IL-6), tumour necrosis factor- $\alpha$ (TNF- $\alpha$ ) and macrophage inflammatory protein-2 (MIP-2) were measured in plasma by enzyme linked immunosorbent assay (ELISA) (Biosource, Camarillo, CA, USA). Lower detection limits for these assays are $8 \mathrm{pg} / \mathrm{mL}, 4 \mathrm{pg} / \mathrm{mL}$ and $1 \mathrm{pg} / \mathrm{mL}$ for IL-6, TNF- $\alpha$ and MIP-2 respectively. Soluble intercellular adhesion molecule-1 (sICAM-1) (R\&D Systems Inc, Minneapolis, MN, USA) and active plasminogen activator inhibitor-1 (aPAI-1) (Innovative Research Inc, Southfield, MI, USA), lower detection limit $0.05 \mathrm{ng} / \mathrm{mL}$ ), were measured in plasma with an ELISA, according to manufacturer guidelines.

After sacrifice, lungs were harvested and the left upper lobe was formalin fixed until further histological analysis. The left lower lobe of the lung was harvested, weighed, and dried overnight in a heated stove. Lung wet to dry (W/D) weight ratio was calculated by dividing wet by the dry lung weight. All left upper lung lobes were transversely cut immediately above the main brochus insertion and random sections, including posterior and anterior parts of the lungs, were assessed by a pathologist blinded to the experimental origin of the specimens. A quantitative morphometric analysis of alveolar collapse, perivascular haemorrhage, alveolar haemorrhage, perivascular oedema, vascular congestion, alveolar polymorphonuclear leukocytes, alveolar oedema and macrophages was performed, as has been described previously [32]. Each item was scored 0-3 (0 = normal; 1 = mild; 2 = moderate; 3 = severe) and then calculated for a total score of lung injury (scores potentially ranging from 0-24) [32].

\section{Statistical analysis}

Data are expressed as mean \pm standard error of the mean. When data were not normally distributed according to a Kolmogorov-Smirnov test ( $p>0.05)$, data were ranked before analysis. The effects of MV in each model were tested using univariate analysis of variance and longitudinal data were compared using generalized estimating equations designed for the analysis of repeated measurements. Post hoc testing was performed according to Bonferroni. Using these tests the effects of the model were analysed for each parameter and these comparisons are described by acid instillation or sepsis. Subsequently the effects of MV were analysed and finally the model-dependent effects were analysed by determining the interaction between model and MV for each parameter. A value of $\mathrm{P}<0.05$ was considered statistically significant, we report exact $\mathrm{p}$-values unless $\mathrm{P}<$ 0.001. All analyses were performed using SPSS 17.0 statistical software (SPSS Inc., Chicago, IL, USA).

\section{Results}

\section{Hemodynamics and arterial blood gas analysis}

Mean arterial pressure (MAP) did not differ between the two models at baseline. MV strategy did not influence MAP at baseline, but, as analyzed by the interaction between model and MV, the LVt sepsis group had a lower MAP compared to the HVt acid group at baseline. During the experiment, the sepsis groups had a lower MAP compared to the acid groups $(\mathrm{P}<0.001)$. No effects of MV strategy or interaction were observed. After $4 \mathrm{~h}$ of $\mathrm{MV}$, however, no effects of model or MV were observed. Analyses of the interaction showed that 
the MAP in the HVt sepsis group was lower than that in the LVt acid group ( $\mathrm{P}=0.01$ ) (Table 1$)$. Heart rate showed a similar pattern, although at baseline animals in the sepsis model had higher heart rates $(P=0.001)$. Towards the end of the experiment, heart rate did not differ among groups (Table 1). No differences in $\mathrm{pH}$ and $\mathrm{P}_{\mathrm{a}} \mathrm{CO}_{2}$ were observed between the models and $\mathrm{MV}$. More importantly, values remained within normal range.

\section{Effects on the lungs}

The $\mathrm{P}_{\mathrm{a}} \mathrm{O}_{2} / \mathrm{F}_{\mathrm{I}} \mathrm{O}_{2}$ ratio was similar among models at baseline and at randomisation (Figure $1 \mathrm{~A}$ ). The $\mathrm{P}_{\mathrm{a}} \mathrm{O}_{2} / \mathrm{F}_{\mathrm{I}} \mathrm{O}_{2}$ ratio was lower after acid instillation than during sepsis $(\mathrm{P}<0.001)$. HVt affected the $\mathrm{P}_{\mathrm{a}} \mathrm{O}_{2} / \mathrm{F}_{\mathrm{I}} \mathrm{O}_{2}$ ratio $(\mathrm{p}<0.001)$, however, as indicated by an interaction between $\mathrm{MV}$ and model ( $\mathrm{p}<0.001$ ), $\mathrm{HVt}$ decreased $\mathrm{P}_{\mathrm{a}} \mathrm{O}_{2} / \mathrm{F}_{\mathrm{I}} \mathrm{O}_{2}$ ratio after acid instillation, but not during sepsis (Figure 1A). At baseline no differences in compliance were observed between the models (Figure 1B). The compliance was lower after acid instillation than during sepsis $(\mathrm{P}<0.001)$ (Figure 1B). There was no effect of $\mathrm{HVt}$ on compliance in both models $(\mathrm{P}=0.68)$, nor were there model dependent effects of $\mathrm{HVt}$, as indicated by the absence of interaction between model and MV $(\mathrm{P}=0.40)$.

\section{The W/D weight ratio and lung histology}

The lung W/D weight ratio was higher after acid instillation than during sepsis $(\mathrm{P}<0.001)$. HVt increased the $\mathrm{W} / \mathrm{D}$ weight ratio $(\mathrm{P}<0.001)$, however, as indicated by an interaction between MV and model $(\mathrm{P}<0.001), \mathrm{HVt}$ increased $\mathrm{W} / \mathrm{D}$ weight ratio after acid instillation, but not during sepsis (Figure 2A). The lung injury score was higher after acid instillation than during sepsis $(\mathrm{P}<$ 0.001). HVt increased the lung injury score $(P<0.001)$, however, as indicated by an interaction between $\mathrm{MV}$ and model ( $\mathrm{P}=0.04)$, HVt increased lung injury score after acid instillation, but not during sepsis (Figure 2B).

\section{Mediators}

Acid instillation increased IL-6 plasma concentrations as compared to sepsis $(\mathrm{P}=0.002)$. No effects of HVt on IL6 plasma concentrations were observed, nor were there model-dependent effects of HVt (Table 2), therefore no significant differences were observed in IL-6 levels between LVt and HVt after acid instillation. Acid instillation increased TNF- $\alpha$ plasma concentrations as compared to sepsis $(\mathrm{P}=0.005)$. HVt had no effects on plasma TNF- $\alpha$ concentrations. Effects of HVt did not depend on the model, i.e. no significant interaction between model and MV was observed (Table 2). Neither the model nor HVt had significant effects on plasma MIP-2 concentration (Table 2) and, additionally, there were no model dependent effects of HVt. Plasma ICAM-1 concentrations were higher during sepsis than after acid instillation $(\mathrm{P}=0.031)$. MV with HVt did not increased plasma ICAM-1 concentrations as compared LVt, nor were there model dependent effects of HVt (Table 2). Neither the model nor MV had significant effects on plasma PAI-1 concentration (Table 2) and, additionally, there were no model dependent effects of $\mathrm{HVt}$.

\section{Discussion}

The major finding of this study is that VILI develops only after $\mathrm{HVt}$ in combination with prior pulmonary

Table 1 Hemodynamics and arterial blood gas analysis.

\begin{tabular}{|c|c|c|c|c|c|}
\hline & & Baseline & $\mathrm{T}=0 \mathrm{hr}$ & $\mathrm{T}=2 \mathrm{hr}$ & $\mathrm{T}=4 \mathrm{hr}$ \\
\hline \multirow[t]{4}{*}{ Mean arterial pressure $(\mathrm{mmHg})$} & LVt acid" & $81 \pm 4.0$ & $84 \pm 3.9$ & $91 \pm 3.8$ & $77 \pm 2.6^{*}$ \\
\hline & HVt acid ${ }^{\#}$ & $77 \pm 3.4$ & $88 \pm 5.5$ & $87 \pm 2.7$ & $72 \pm 2.3$ \\
\hline & LVt sepsis & $75 \pm 1.7$ & $74 \pm 2.6$ & $68 \pm 2.2$ & $69 \pm 2.5$ \\
\hline & HVt sepsis & $74 \pm 2.2$ & $80 \pm 2.2$ & $66 \pm 2.1$ & $65 \pm 0.9$ \\
\hline \multirow[t]{4}{*}{ Heart rate (bpm) } & LVt acid & $269 \pm 10$ & $267 \pm 11$ & $332 \pm 10$ & $336 \pm 12$ \\
\hline & HVt acid & $289 \pm 8$ & $249 \pm 14$ & $328 \pm 7$ & $345 \pm 11$ \\
\hline & LVt sepsis & $322 \pm 9^{\$}$ & $322 \pm 9$ & $346 \pm 15$ & $353 \pm 8$ \\
\hline & HVt sepsis & $350 \pm 14^{\$}$ & $360 \pm 12$ & $361 \pm 10$ & $350 \pm 9$ \\
\hline \multirow[t]{4}{*}{$\mathrm{pH}$} & LVt acid & $7.41 \pm 0.02$ & $7.39 \pm 0.01$ & $7.37 \pm 0.01$ & $7.35 \pm 0.01$ \\
\hline & HVt acid & $7.41 \pm 0.02$ & $7.38 \pm 0.01$ & $7.40 \pm 0.01$ & $7.30 \pm 0.02$ \\
\hline & LVt sepsis & $7.44 \pm 0.01$ & $7.42 \pm 0.01$ & $7.38 \pm 0.02$ & $7.33 \pm 0.02$ \\
\hline & HVt sepsis & $7.44 \pm 0.01$ & $7.44 \pm 0.01$ & $7.41 \pm 0.02$ & $7.38 \pm 0.02$ \\
\hline \multirow[t]{4}{*}{$\mathrm{P}_{\mathrm{a}} \mathrm{CO}_{2}(\mathrm{mmHg})$} & LVt acid & $39.4 \pm 1.1$ & $42.9 \pm 1.8$ & $42.4 \pm 1.4$ & $42.2 \pm 1.4$ \\
\hline & HVt acid & $40.0 \pm 1.2$ & $43.8 \pm 2.3$ & $40.3 \pm 1.3$ & $45.8 \pm 2.1$ \\
\hline & LVt sepsis & $37.1 \pm 0.8$ & $38.7 \pm 1.78$ & $38.0 \pm 1.0$ & $42.2 \pm 1.0$ \\
\hline & HVt sepsis & $37.0 \pm 1.5$ & $38.7 \pm 1.6$ & $36.0 \pm 0.7$ & $36.0 \pm 0.6$ \\
\hline
\end{tabular}

Mean arterial pressure (MAP) and heart rate in rats during $4 \mathrm{~h}$ of mechanical ventilation after acid instillation or during sepsis with low tidal volume (LVt) (6 $\mathrm{mL} /$ $\mathrm{kg})$, with a positive end-expiratory pressure (PEEP) of $5 \mathrm{~cm} \mathrm{H} \mathrm{H}_{2} \mathrm{O}$ or high tidal volume $(\mathrm{HVt})(15 \mathrm{~mL} / \mathrm{kg})$ without PEEP. Data represent mean $\pm \mathrm{SEM}$. ${ }^{\#} \mathrm{p}<0.001 \mathrm{for}$ model compared to sepsis during the experiment, ${ }^{*} p=0.01$ compared to HVt sepsis, ${ }^{\$} p=0.001$ for model compared to acid only at baseline. 

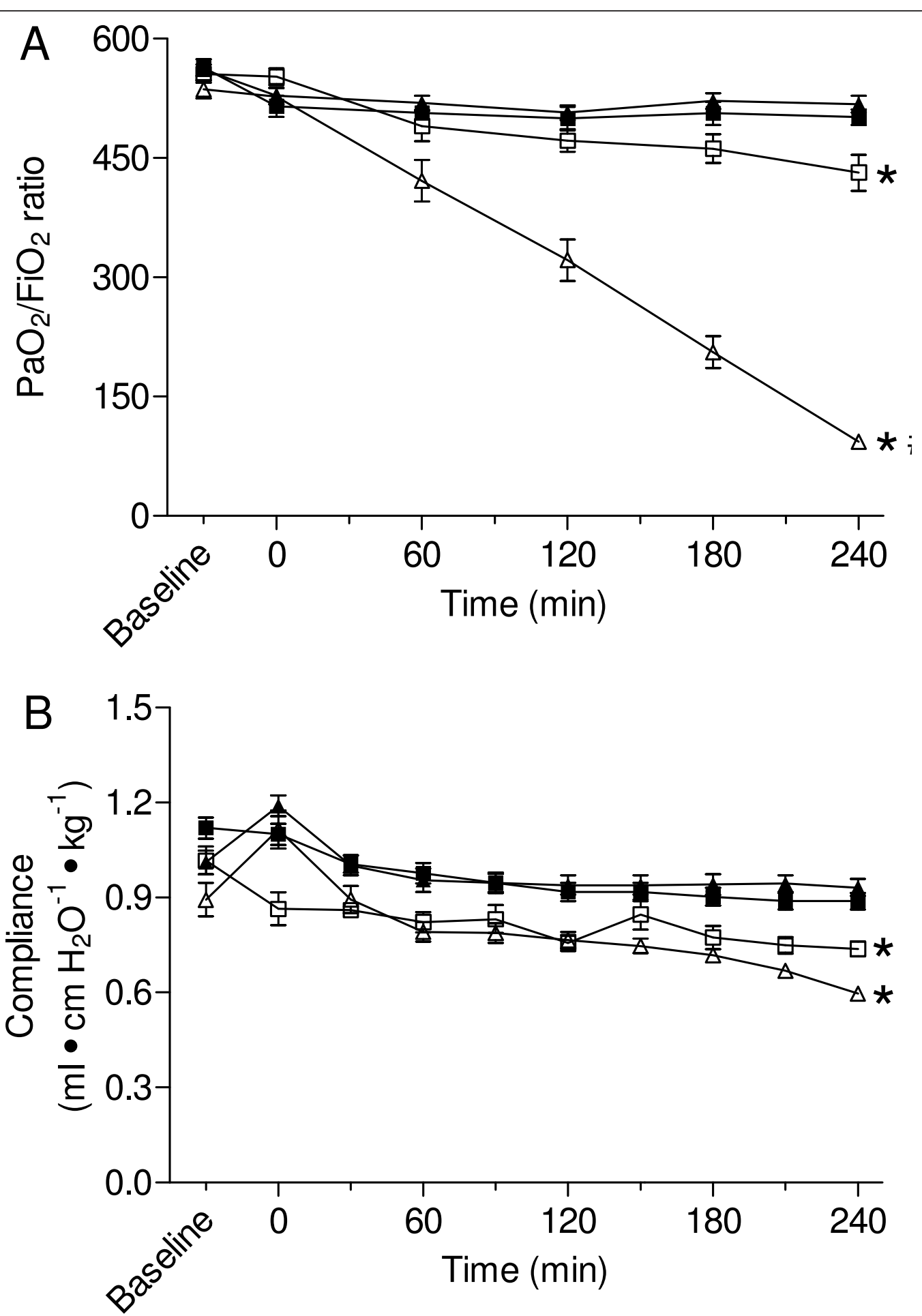

Figure $1 \mathrm{P}_{\mathrm{a}} \mathrm{O}_{2} / \mathrm{F}_{1} \mathrm{O}_{2}$ ratio and lung compliance. The $\mathrm{P}_{\mathrm{a}} \mathrm{O}_{2} / \mathrm{F}_{1} \mathrm{O}_{2}$ ratio and compliance in rats ventilated for $4 \mathrm{~h}$ after acid instillation or during

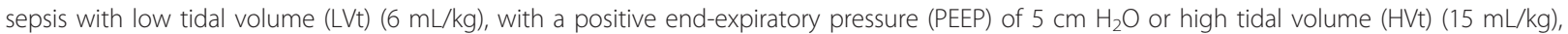
without PEEP. (A) $\mathrm{P}_{\mathrm{a}} \mathrm{O}_{2} / \mathrm{F}_{1} \mathrm{O}_{2}$ ratio decreased after acid instillation irrespective of ventilation strategy. Mechanical ventilation (MV) after acid instillation decreased the $\mathrm{P}_{a} \mathrm{O}_{2} / \mathrm{F}_{1} \mathrm{O}_{2}$ ratio in contrast to HVt MV during sepsis. (B) Acid instillation decreased lung compliance as opposed to sepsis. No effects of MV were observed. ${ }^{*} p<0.001$ for model compared to LVt and HVt sepsis, $\# p<0.001$ for interaction between model and MV. Open squares: LVt acid, open triangles: HVt acid, solid squares: LVt sepsis and solid triangles: HVt sepsis. 


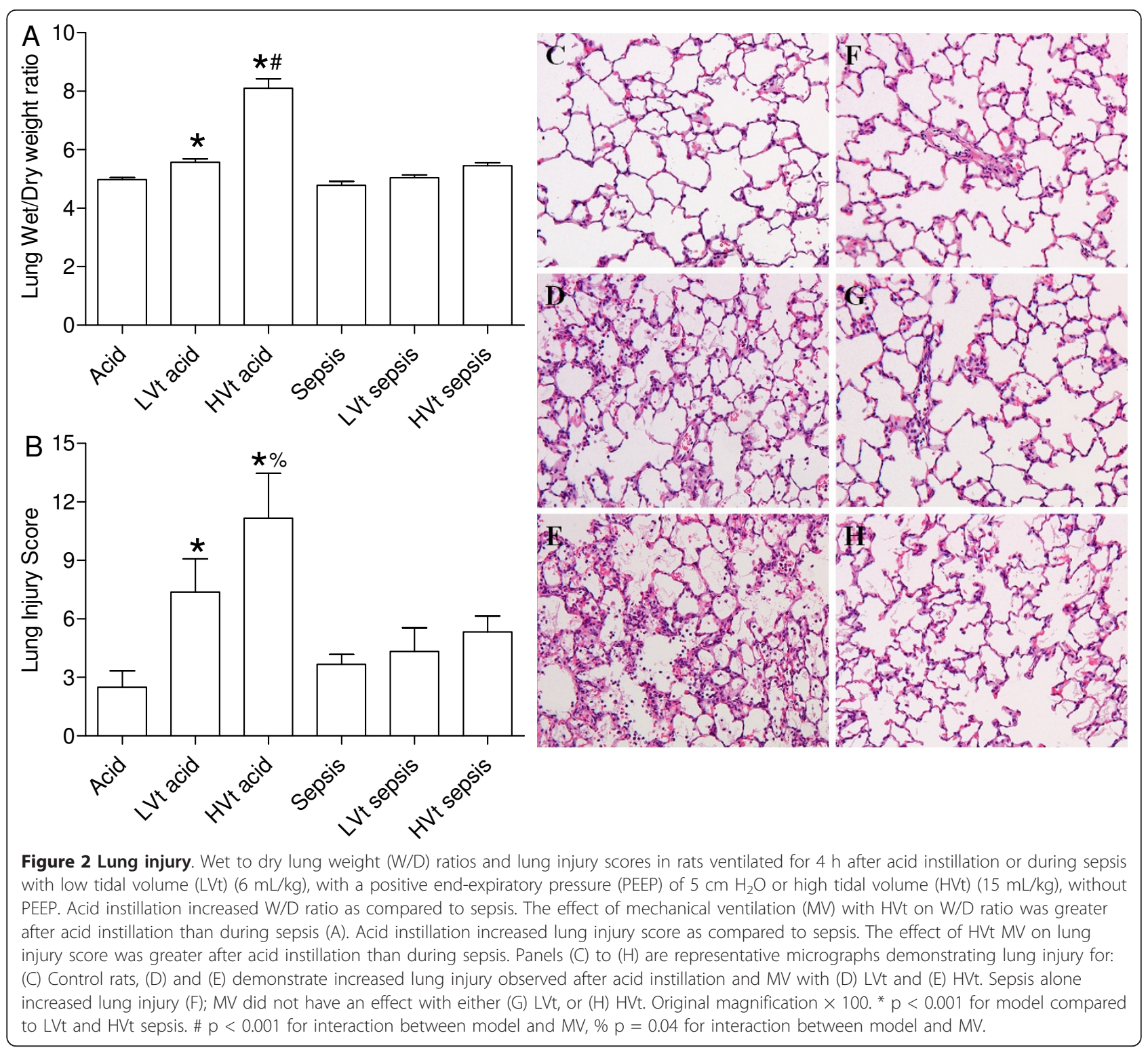

Table 2 Plasma concentrations of mediators.

\begin{tabular}{cllllll}
\hline & Acid & LVt acid & HVt acid & Sepsis & LVt sepsis & HVt sepsis \\
\hline IL-6 $(\mathrm{pg} / \mathrm{ml})$ & $321 \pm 13$ & $1113 \pm 387^{\#}$ & $758 \pm 209^{\#}$ & $312 \pm 8$ & $643 \pm 190$ & $393 \pm 31$ \\
TNF- $\alpha(\mathrm{pg} / \mathrm{ml})$ & $39 \pm 3$ & $61 \pm 9^{*}$ & $62 \pm 12^{*}$ & $38 \pm 2$ & $42 \pm 4$ & $43 \pm 10$ \\
MIP-2 $(\mathrm{pg} / \mathrm{ml})$ & $4.6 \pm 0.1$ & $5.4 \pm 0.4$ & $5.2 \pm 0.03$ & $4.7 \pm 0.3$ & $5.0 \pm 0.3$ & $6.0 \pm 0.8$ \\
SICAM-1 $(\mathrm{ng} / \mathrm{ml})$ & $4.0 \pm 0.3$ & $30.9 \pm 2.8^{\$}$ & $22.6 \pm 2.8^{\$}$ & $31.4 \pm 6.0$ & $41.2 \pm 6.7$ & $32.2 \pm 2.4$ \\
aPAl-1 $(\mathrm{ng} / \mathrm{ml})$ & $0.0 \pm 0.0$ & $20.8 \pm 2.1$ & $12.5 \pm 5.7$ & $9.8 \pm 3.0$ & $18.5 \pm 2.7$ & $22.5 \pm 3.1$ \\
\hline
\end{tabular}

Plasma concentrations of interleukin-6 (IL-6), tumour necrosis factor- $\alpha$ (TNF- $\alpha$ ), macrophage inflammatory protein-2 (MIP-2), soluble intercellular adhesion molecule-1 (sICAM-1) and active plasminogen activator inhibitor-1 (aPAl-1) in rats ventilated for $4 \mathrm{~h}$ after acid instillation or during sepsis with low tidal volume (LVt) $(6 \mathrm{~mL} / \mathrm{kg})$, with a positive end-expiratory pressure (PEEP) of $5 \mathrm{~cm} \mathrm{H} \mathrm{H}_{2} \mathrm{O}$ or high tidal volume (HVt) $(15 \mathrm{~mL} / \mathrm{kg}) \mathrm{without} \mathrm{PEEP}$. HVt after acid instillation did not affect plasma mediator levels. Acid instillation increased IL- 6 and TNF- $\alpha$ plasma concentrations as compared to sepsis. Levels of sICAM-1 were lower in the acid group. Data represent mean \pm SEM. ${ }^{\#} p=0.002$ for model compared to LVt and HVt sepsis, ${ }^{*} p=0.005$ for model compared to LVt and HVt sepsis, $\$ p=0.031$ for model compared to LVt and HVt sepsis. 
acid instillation as shown by decreased $\mathrm{P}_{\mathrm{a}} \mathrm{O}_{2} / \mathrm{F}_{\mathrm{I}} \mathrm{O}_{2}$ ratio, increased $\mathrm{W} / \mathrm{D}$ weight ratio and histological lung injury score. In contrast however, plasma mediator concentrations did not reflect this difference between the effects of HVt MV.

In this study we set out to examine the effects of different ventilatory strategies on lung injury and systemic mediator release in direct and indirect pulmonary injury in rats. This first warrants further explanation of the experimental models we used in this study. It is well known that both MV following acid instillation and MV during sepsis cause different degrees of acute lung injury assessed by histological examination [33]. Following intratracheal instillation of acid an acute inflammatory response in the lung develops within minutes, and a delayed injury usually develops $18 \mathrm{~h}$ after cecal ligation and puncture $[17,33]$. The intratracheal acid instillation model primarily targets the alveolar epithelium (direct injury) and can be used in conjuction with MV to further reproduce clinically relevant scenarios [22,33]. In humans, aspiration of gastric contents involves more than hydrochloric acid alone and the narrow difference between injurious and non-injurious acid concentrations is a potential disadvantage [33]. We therefore did a pilot study to determine the appropriate acid concentration. CLP-induced polymicrobial sepsis is one of the best and most widely used animal models for sepsis and organ injury, including lung injury, that mainly targets the endothelium (indirect hit) [33]. However, this model requires surgery and the bacterial inoculum is unknown [33]. Second, the two ventilation strategies we used in this study may require further explanation. For LVt ventilation we used $6 \mathrm{ml} / \mathrm{kg}$ with a PEEP of $5 \mathrm{~cm} \mathrm{H}_{2} \mathrm{O}$, a strategy that is used frequently and generally considered to be relatively non-injurious $[16,32,34]$. We compared $\mathrm{LVt}$ ventilation to a strategy that is generally considered to be injurious. Both the increased tidal volume of 15 $\mathrm{ml} / \mathrm{kg}$ and the absence of PEEP contribute to the injurious nature of this strategy [15]. According to the literature, a Vt exceeding $15 \mathrm{ml} / \mathrm{kg}$ in the absence of PEEP would likely increase premature death rate [15]. In contrast, during sepsis, when lungs are not hit directly, for lung injury to occur, a Vt of more than $15 \mathrm{ml} / \mathrm{kg}$ may be needed to further injure the lungs [17]. However, recent reports have shown that a Vt of only $8 \mathrm{ml} / \mathrm{kg}$ may be injurious in previously healthy mice $[30,35]$. To balance between injury and mortality we therefore used an injurious strategy using a Vt of $15 \mathrm{ml} / \mathrm{kg}$ without PEEP.

The results of our study indicate that at the onset of randomization to HVt or LVt both groups had normal $\mathrm{P}_{\mathrm{a}} \mathrm{O}_{2} / \mathrm{F}_{\mathrm{I}} \mathrm{O}_{2}$ ratios and compliance, suggesting that there was little or no acute lung injury at that time. Although we did not perform a histological analysis at randomization it is likely that some degree of subclinical lung injury at randomization may have been present that was not reflected by oxygenation criteria. In line with this are the histological changes that were observed in the sepsis control group. As we hypothesized, the effects of the same HVt ventilatory strategy differed depending on the type of underlying pulmonary injury. Exposing lungs to $4 \mathrm{~h}$ of $\mathrm{HVt} \mathrm{MV}$ revealed that profound VILI only occurred in the acid instillation group as compared to HVt MV during sepis. This was exemplified by a decreased $\mathrm{P}_{\mathrm{a}} \mathrm{O}_{2} / \mathrm{F}_{\mathrm{I}} \mathrm{O}_{2}$ ratio and compliance and increased histological lung injury score and W/D weight ratio. In contrast, LVt after acid instillation was not associated with VILI. During sepsis however, $\mathrm{HVt}$ ventilation did not decrease $\mathrm{P}_{\mathrm{a}} \mathrm{O}_{2} / \mathrm{F}_{\mathrm{I}} \mathrm{O}_{2}$ ratio and compliance, nor did it increase lung W/D weight ratio and lung injury score as compared to LVt MV during sepsis.

The results of the present study thus indicate that acid instillation and MV with a HVt, but not sepsis and $\mathrm{HVt}$, synergistically lead to severe VILI. Acid instillation and sepsis, thus, prime the lungs differently and render lungs exposed to the former type of injury more susceptible to HVt VILI. This may be explained by the fact that in direct lung injury pulmonary alveolar filling by oedema, fibrin, collagen neutrophilic aggregates and/or blood leading to consolidation predominates [2,10-12]. Therefore it is likely that $\mathrm{HVt}$ ventilation after acid instillation, with a tidal volume distributed over a smaller aerated lung volume, led to repeated alveolar overdistension and subsequent aggravation of lung injury. In contrast, interstitial oedema and collapse may predominate in sepsis and HVt did therefore not further injure the lungs. This is supported by the increased lung injury score after HVt and acid instillation compared to sepsis, of which most items, such as alveolar haemorrhage and inflammatory cell infiltration, are associated with pulmonary consolidation. In line with this concept are observations made by Herrera et al. [17]. They observed lung injury only when tidal volumes of at least $20 \mathrm{ml} / \mathrm{kg}$ were used after CLP and they found mainly perivascular oedema and only moderate acute inflammatory infiltrates [17]. Others, however, have shown VILI during sepsis, but these studies applied much higher tidal volumes, ranging from $20-35 \mathrm{ml} / \mathrm{kg}$, than we did [36-38]. Similarly, Altemeier et al, showed that MV with a tidal volume of $15 \mathrm{ml} / \mathrm{kg}$ after systemic lipopolysaccharide (LPS) did not cause gross histological changes [25]. In contrast, Chiumello et al. showed severe lung injury and premature death after MV with $16 \mathrm{ml} / \mathrm{kg}$ without PEEP following acid instillation [15].

The second objective of our study was to to examine the effects of different ventilatory strategies on systemic mediator release. The systemic inflammatory response, in contrast to the pulmonary inflammatory response 
after different MV strategies following indirect and direct lung injury has been studied scarcely. For example, in a mouse model of direct (intra-tracheal endotoxin) and indirect (intra-peritoneal endotoxin) lung injury, Menezes et al. observed higher pulmonary IL-6, TNF- $\alpha$ mRNA and cellularity in bronchoalveolar lavage fluid in the former. They did not analyze blood levels, nor the effect of MV strategy [4]. Although Haitsma et al. administered LPS intratracheally and intraperitoneally to rats and showed that different PEEP levels ( 0 or 10 $\mathrm{cm} \mathrm{H}_{2} \mathrm{O}$ ) affected systemic TNF- $\alpha$ levels differently, they did not study other important mediators of systemic inflammation and only used high peak inspiratory pressures of $45 \mathrm{~cm} \mathrm{H}_{2} \mathrm{O}$ [28]. Therefore, the differential effects of more clinically relevant MV strategies on decompartmentalization, i.e. the transfer of mediators from the intrapulmonary compartment to the systemic circulation, remain largely unknown. In our study, plasma mediator levels only partly reflected the differences in effects of ventilatory strategy on lung injury. The direct pulmonary insult (acid instillation) was associated with a greater increase in plasma IL- 6 and TNF- $\alpha$ concentrations, but the indirect pulmonary insult (sepsis) resulted in increased plasma ICAM-1 concentrations. In contrast to parameters of lung injury however, $\mathrm{HVt}$ ventilation after acid instillation did not have an additional effect on mediator levels. Thus, in contrast to our hypothesis, MV induced systemic mediator release did not depend on the underlying type of lung injury. MV after acid instillation has previously shown to increase pro-inflammatory mediators such as IL-6 and TNF- $\alpha$ during MV [15]. The effects of MV on systemic mediator release during sepsis are less clear. For example, Herrera et al. showed that HVt ventilation during sepsis increased plasma TNF- $\alpha$ levels compared to LVt with PEEP but not to sepsis alone. In contrast, plasma IL-6 levels were increased after HVt ventilation compared to sepsis alone but not to LVt with PEEP [17]. Previously, we showed in healthy rats that different ventilation strategies affected lung histology without altering systemically circulating IL-6 levels [39] and similar results have been found by others [25]. After acid instillation, LVt MV may be sufficient for decompartmentalization to occur or HVt MV induced VILI was not severe enough since our levels of plasma TNF- $\alpha$ are lower after HVt MV than previously reported [15]. In sepsis HVt MV may not have been severe enough as reported previously by Herrera et al [17]. The systemic cytokine release during $\mathrm{MV}$ has been a topic of debate [40], differences in models, type and severity of lung injury and ventilatory settings may have led to different decompartmentalization in our study as compared to others $[15,17,28]$. Also, during sepsis the choice of mediators further complicates the debate, since different mediators have different patterns of excretion [41].

Our study has several limitations. We set out to test the hypothesis that harmful effects of different ventilation strategies depend on the type of underlying lung injury. Since most ICU patients requiring MV have underlying lung injury, we compared the effects of different MV strategies during indirect and direct lung injury. We therefore did not include healthy ventilated controls, time-matched non-ventilated sepsis controls were included. However, due ethical and technical limitations we were unable to include a time-matched control group for the acid instillation group. One may argue therefore that differences in severity of the first insult may account for the differential effects of $\mathrm{HVt}$ after acid instillation and during sepsis. However, histological analysis of lung injury directly after acid instillation showed only a marginally increased lung injury score. Prior to MV there were no indications that there was a difference in severity of the insults since oxygenation and lung compliance were comparable among the groups. Additionally, the different pathophysiologic mechanisms between direct and indirect lung injury make comparison of the severity of the initial insult in terms of lung injury precarious. Furthermore, the sole effect of MV on mediator levels in acid aspiration could not be determined. We did not make longitudinal measurements, so cannot completely exclude an interaction between type of pulmonary injury and MV on the course of plasma mediators. Gattinoni et al, observed different responses to PEEP between direct and indirect lung injury in patients previously [2]. We compared two ventilation strategies frequently used to study the effects of VILI; but did not further evaluate the role of PEEP.

\section{Conclusions}

In conclusion, rats subjected to ventilation with $\mathrm{HVt}$ are more susceptible to VILI after pulmonary priming with acid instillation than after sepsis-induced lung injury. However, this difference in response was not observed in the systemic release of mediators. Therefore, the adverse effects of MV can differ between direct and indirect lung injury, and our data support even more cautious ventilator management in the former. Additionally, systemic mediator levels are not indicative for the severity of VILI. Further evaluation of the interaction between aetiology of acute lung injury, MV and systemic release of pulmonary inflammatory mediators in patients seems warranted.

\section{Key messages}

- Lungs are more susceptible to ventilator induced injury after acid instillation than during sepsis 
- The adverse effects of mechanical ventilation can differ between lungs exposed to direct or indirect lung injury

- Systemic mediator levels are not indicative for the severity of ventilator induced lung injury

\section{List of abbreviations}

aPAl: active plasminogen activator inhibitor; ARDS: acute respiratory distress syndrome; ELISA: enzyme-linked immuno sorbent assay; HVt: high tidal volume; IL: interleukin; LPS: lipopolysaccharide; LVt: low tidal volume; MAP: mean arterial pressure; MIP: macrophage inflammatory protein; MV: mechanical ventilation; PEEP: positive end-expiratory pressure; SICAM: soluble intercellular adhesion molecule; TNF: tumor necrosis factor; VILI: ventilatorinduced lung injury; Vt: tidal volume; W/D: wet to dry weight.

\section{Acknowledgements}

Supported by an award from the Canadian Institutes of Health Research (CIHR) to A.S.S., and the Ter Meulen Fund, Royal Netherlands Academy of Arts and Sciences, The Netherlands to J.W.K.

\section{Author details}

${ }^{1}$ From the Department of Paediatric Intensive Care, VU University Medical Centre, Amsterdam, The Netherlands. ${ }^{2}$ Department of Anaesthesia and Interdepartmental Division of Critical Care Medicine, The Keenan Research Centre at the Li Ka Shing Knowledge Institute of St. Michael's Hospital. ${ }^{3}$ Department of Paediatrics, Tergooiziekenhuizen, Blaricum, The Netherlands. ${ }^{4}$ Intensive Care, VU University Medical Centre, Amsterdam, The Netherlands. ${ }^{5}$ Department of Laboratory Medicine, University of Toronto, Toronto, Ontario, Canada. ${ }^{6}$ Departments of Anaesthesiology and Critical Care Medicine, University of Eastern Piedmont, Novara, Italy.

\section{Authors' contributions}

JWK, FBP, ABG and AS conceived the study, planned the overall experimental design and wrote the manuscript. JWK and JH carried out the experiments; SJ's input was critical for the section on histology and advised on morphogical studies. RV and $\mathrm{HZ}$ advised in the experimental design. All authors have read and approved the final manuscript.

\section{Competing interests}

The authors declare that they have no competing interests.

Received: 1 June 2011 Accepted: 28 December 2011

Published: 28 December 2011

\section{References}

1. Bernard GR, Artigas A, Brigham KL, Carlet J, Falke K, Hudson L, Lamy M, Legall JR, Morris A, Spragg R: The American-European Consensus Conference on ARDS. Definitions, mechanisms, relevant outcomes, and clinical trial coordination. Am J Respir Crit Care Med 1994, 149:818-824.

2. Gattinoni L, Pelosi P, Suter PM, Pedoto A, Vercesi P, Lissoni A: Acute respiratory distress syndrome caused by pulmonary and extrapulmonary disease. Different syndromes? Am J Respir Crit Care Med 1998, 158:3-11.

3. Leite-Junior JH, Garcia CS, Souza-Fernandes AB, Silva PL, Ornellas DS, Larangeira AP, Castro-Faria-Neto HC, Morales MM, Negri EM, Capelozzi VL, et al: Methylprednisolone improves lung mechanics and reduces the inflammatory response in pulmonary but not in extrapulmonary mild acute lung injury in mice. Crit Care Med 2008, 36:2621-2628.

4. Menezes SL, Bozza PT, Neto HC, Laranjeira AP, Negri EM, Capelozzi VL, Zin WA, Rocco PR: Pulmonary and extrapulmonary acute lung injury: inflammatory and ultrastructural analyses. J Appl Physiol 2005, 98:1777-1783.

5. Kloot TE, Blanch L, Melynne YA, Weinert C, Adams AB, Marini JJ, Shapiro RS, Nahum $A$ : Recruitment maneuvers in three experimental models of acute lung injury. Effect on lung volume and gas exchange. Am J Respir Crit Care Med 2000, 161:1485-1494.

6. DiRocco JD, Pavone LA, Carney DE, Lutz CJ, Gatto LA, Landas SK, Nieman GF: Dynamic alveolar mechanics in four models of lung injury. Intensive Care Med 2006, 32:140-148.
7. Rocker GM: Acute respiratory distress syndrome: different syndromes, different therapies? Crit Care Med 2001, 29:210-211.

8. Pelosi P, Gattinoni L: Acute respiratory distress syndrome of pulmonary and extra-pulmonary origin: fancy or reality? Intensive Care Med 2001, 27:457-460.

9. Constantin JM, Grasso S, Chanques G, Aufort S, Futier E, Sebbane M, Jung B, Gallix B, Bazin JE, Rouby JJ, et al: Lung morphology predicts response to recruitment maneuver in patients with acute respiratory distress syndrome. Crit Care Med 2010, 38:1108-1117.

10. Pelosi P, D'Onofrio D, Chiumello D, Paolo S, Chiara G, Capelozzi VL, Barbas CS, Chiaranda M, Gattinoni L: Pulmonary and extrapulmonary acute respiratory distress syndrome are different. Eur Respir J Suppl 2003, 42:48s-56s

11. Mertens M, Tabuchi A, Meissner S, Krueger A, Schirrmann K, Kertzscher U, Pries AR, Slutsky AS, Koch E, Kuebler WM: Alveolar dynamics in acute lung injury: heterogeneous distension rather than cyclic opening and collapse. Crit Care Med 2009, 37:2604-2611.

12. Rocco PR, Zin WA: Pulmonary and extrapulmonary acute respiratory distress syndrome: are they different? Curr Opin Crit Care 2005, 11:10-17.

13. Eisner MD, Thompson T, Hudson LD, Luce JM, Hayden D, Schoenfeld D, Matthay MA: Efficacy of low tidal volume ventilation in patients with different clinical risk factors for acute lung injury and the acute respiratory distress syndrome. Am J Respir Crit Care Med 2001 164:231-236.

14. Thille AW, Richard JC, Maggiore SM, Ranieri VM, Brochard L: Alveolar recruitment in pulmonary and extrapulmonary acute respiratory distress syndrome: comparison using pressure-volume curve or static compliance. Anesthesiology 2007, 106:212-217.

15. Chiumello D, Pristine G, Slutsky AS: Mechanical ventilation affects local and systemic cytokines in an animal model of acute respiratory distress syndrome. Am J Respir Crit Care Med 1999, 160:109-116.

16. Gurkan OU, O'Donnell C, Brower R, Ruckdeschel E, Becker PM: Differential effects of mechanical ventilatory strategy on lung injury and systemic organ inflammation in mice. Am J Physiol Lung Cell Mol Physiol 2003, 285 L710-L718.

17. Herrera MT, Toledo C, Valladares F, Muros M, Diaz-Flores L, Flores C, Villar J: Positive end-expiratory pressure modulates local and systemic inflammatory responses in a sepsis-induced lung injury model. Intensive Care Med 2003, 29:1345-1353.

18. Imai Y, Parodo J, Kajikawa O, de Perrot M, Fischer S, Edwards V, Cutz E, Liu M, Keshavjee S, Martin TR, et al: Injurious mechanical ventilation and end-organ epithelial cell apoptosis and organ dysfunction in an experimental model of acute respiratory distress syndrome. JAMA 2003, 289:2104-2112.

19. Kuiper JW, Groeneveld AB, Slutsky AS, Plotz FB: Mechanical ventilation and acute renal failure. Crit Care Med 2005, 33:1408-1415.

20. Plotz FB, Slutsky AS, van Vught AJ, Heijnen CJ: Ventilator-induced lung injury and multiple system organ failure: a critical review of facts and hypotheses. Intensive Care Med 2004, 30:1865-1872.

21. Hudson LD, Milberg JA, Anardi D, Maunder RJ: Clinical risks for development of the acute respiratory distress syndrome. Am J Respir Crit Care Med 1995, 151:293-301.

22. Folkesson HG, Matthay MA, Hebert CA, Broaddus VC: Acid aspirationinduced lung injury in rabbits is mediated by interleukin-8-dependent mechanisms. J Clin Invest 1995, 96:107-116.

23. Doyle RL, Szaflarkki N, Modin GW, Wiener-Kronish JP, Matthay MA: Identification of patients with acute lung injury. Predictors of mortality. Am J Respir Crit Care Med 1995, 152:1818-1824.

24. Pepe PE, Potkin RT, Reus DH, Hudson LD, Carrico CJ: Clinical predictors of the adult respiratory distress syndrome. Am J Surg 1982, 144:124-130.

25. Altemeier WA, Matute-Bello G, Frevert CW, Kawata Y, Kajikawa O, Martin TR, Glenny RW: Mechanical ventilation with moderate tidal volumes synergistically increases lung cytokine response to systemic endotoxin. Am J Physiol Lung Cell Mol Physiol 2004, 287:L533-L542.

26. Bregeon F, Delpierre S, Chetaille B, Kajikawa O, Martin TR, Autillo-Touati A, Jammes $Y$, Pugin J: Mechanical ventilation affects lung function and cytokine production in an experimental model of endotoxemia. Anesthesiology 2005, 102:331-339.

27. Calfee CS, Eisner MD, Parsons PE, Thompson BT, Conner ER Jr, Matthay MA, Ware LB: Soluble intercellular adhesion molecule- 1 and clinical outcomes in patients with acute lung injury. Intensive Care Med 2008, 35:248-257. 
28. Haitsma JJ, Uhlig S, Goggel R, Verbrugge SJ, Lachmann U, Lachmann B: Ventilator-induced lung injury leads to loss of alveolar and systemic compartmentalization of tumor necrosis factor-alpha. Intensive Care Med 2000, 26:1515-1522.

29. Meduri GU, Kohler G, Headley S, Tolley E, Stentz F, Postlethwaite A: Inflammatory cytokines in the BAL of patients with ARDS. Persistent elevation over time predicts poor outcome. Chest 1995, 108:1303-1314.

30. Vaneker M, Santosa JP, Heunks LM, Halbertsma FJ, Snijdelaar DG, van Egmond J, van den Brink I, VAN DE Pol FM, van der Hoeven JG, Scheffer GJ: Isoflurane attenuates pulmonary interleukin-1 beta and systemic tumor necrosis factor-alpha following mechanical ventilation in healthy mice. Acta Anaesthesiol Scand 2009, 53:742-748.

31. Ware LB, Matthay MA, Parsons PE, Thompson BT, Januzzi JL, Eisner MD: Pathogenetic and prognostic significance of altered coagulation and fibrinolysis in acute lung injury/acute respiratory distress syndrome. Crit Care Med 2007, 35:1821-1828.

32. Vaschetto R, Kuiper JW, Chiang SR, Haitsma JJ, Juco JW, Uhlig S, Plotz FB, Corte FD, Zhang H, Slutsky AS: Inhibition of poly(adenosine diphosphateribose) polymerase attenuates ventilator-induced lung injury. Anesthesiology 2008, 108:261-268.

33. Matute-Bello G, Frevert CW, Martin TR: Animal models of acute lung injury. Am J Physiol Lung Cell Mol Physiol 2008, 295:L379-L399.

34. Vaschetto R, Kuiper JW, Musters RJ, Eringa EC, Della CF, Murthy K, Groeneveld AB, Plotz FB: Renal hypoperfusion and impaired endotheliumdependent vasodilation in an animal model of VILI: the role of the peroxynitrite-PARP pathway. Crit Care 2010, 14:R45.

35. Vaneker M, Halbertsma FJ, van Egmond J, Netea MG, Dijkman HB, Snijdelaar DG, Joosten LA, van der Hoeven JG, Scheffer GJ: Mechanical ventilation in healthy mice induces reversible pulmonary and systemic cytokine elevation with preserved alveolar integrity: an in vivo model using clinical relevant ventilation settings. Anesthesiology 2007, 107:419-426.

36. Nin N, Lorente JA, Fernandez-Segoviano P, De PM, Ferruelo A, Esteban A: High-tidal volume ventilation aggravates sepsis-induced multiorgan dysfunction in a dexamethasone-inhibitable manner. Shock 2009, 31:429-434.

37. Yang CL, Chen CH, Tsai PS, Wang TY, Huang CJ: Protective effects of dexmedetomidine-ketamine combination against ventilator-induced lung injury in endotoxemia rats. J Surg Res 2011, 167:e273-e281.

38. Hu G, Malik AB, Minshall RD: Toll-like receptor 4 mediates neutrophil sequestration and lung injury induced by endotoxin and hyperinflation. Crit Care Med 2010, 38:194-201.

39. Kuiper JW, Versteilen AM, Niessen HW, Vaschetto RR, Sipkema P, Heijnen CJ, Groeneveld AB, Plotz FB: Production of endothelin-1 and reduced blood flow in the rat kidney during lung-injurious mechanical ventilation. Anesth Analg 2008, 107:1276-1283.

40. Dreyfuss D, Ricard JD, Saumon G: On the physiologic and clinical relevance of lung-borne cytokines during ventilator-induced lung injury. Am J Respir Crit Care Med 2003, 167:1467-1471.

41. Orman MA, Nguyen $\Pi$, lerapetritou MG, Berthiaume F, Androulakis IP: Comparison of the cytokine and chemokine dynamics of the early inflammatory response in models of burn injury and infection. Cytokine 2011, 55:362-371.

\section{Pre-publication history}

The pre-publication history for this paper can be accessed here: http://www.biomedcentral.com/1471-2253/11/26/prepub

doi:10.1186/1471-2253-11-26

Cite this article as: Kuiper et al:: High tidal volume mechanical ventilation-induced lung injury in rats is greater after acid instillation than after sepsis-induced acute lung injury, but does not increase systemic inflammation: an experimental study. BMC Anesthesiology 2011 $11: 26$

\section{Submit your next manuscript to BioMed Central and take full advantage of:}

- Convenient online submission

- Thorough peer review

- No space constraints or color figure charges

- Immediate publication on acceptance

- Inclusion in PubMed, CAS, Scopus and Google Scholar

- Research which is freely available for redistribution

Submit your manuscript at www.biomedcentral.com/submit
Biomed Central 